\title{
Televisão universitária, visibilidade e consumo: - papel das redes sociais na promoção dos conteúdos
}

\section{University television, visibility and consumption: the role of social networks in promoting content}

Ana Silvia Lopes Davi Médola ${ }^{1}$

Mariane Frascareli Lelis ${ }^{2}$

Resumo: As emissoras de televisão brasileiras não hegemônicas como as TVs universitárias encontram no contexto midiático atual a possibilidade de novos fluxos de distribuição de conteúdos em relação aos estruturados no sistema analógico. Isso porque a convergência digital, aliada ao surgimento das redes sociais, são recursos potenciais de promoção da visibilidade dos seus programas, pois favorecem a divulgação dos conteúdos disponibilizados aos diversos públicos. Sob o olhar semiótico dos regimes das interações sociais e de visibilidade, o presente trabalho analisa as estratégias adotadas pela TV Unesp nas redes sociais e identifica uma lógica de disseminação de conteúdos subordinada aos propósitos comerciais dessas plataformas. A análise dos resultados das publicações no Facebook para a promoção da visibilidade evidencia como a lógica da monetização operada pelos algoritmos reafirma, no ecossistema das redes sociais, a hegemonia das organizações comerciais dos meios de comunicação.

Palavras-chave: televisão universitária; TV Unesp; visibilidade; semiótica; redes sociais.

Abstract: Non-hegemonic Brazilian television stations such as university TVs find in the current media context the possibility of new content distribution flows

1 Universidade Estadual Paulista Júlio de Mesquita Filho (Unesp). Bauru, SP, Brasil. https://orcid.org/0000-0003-2101-3727. E-mail: asilvia@faac.unesp.br

2 Universidade Estadual Paulista Júlio de Mesquita Filho (Unesp). Bauru, SP, Brasil. https://orcid.org/0000-0002-3356-0245.E-mail: mariane_lelis@yahoo.com.br 
in relation to those structured in the analogue system. This is because digital convergence, coupled with the emergence of social networks, are potential resources to promote the visibility of their programs, as they favor the dissemination of the contents available to different audiences. Under the semiotic look of social interaction and visibility regimes, the present project analyzes the strategies adopted by TV Unesp in social networks and identifies a content dissemination logic subordinated to the commercial purposes of these platforms. The analysis of the results of the publications on Facebook to promote visibility shows how the logic of algorithm-driven monetization reaffirms the hegemony of commercial media organizations in the ecosystem of social networks.

Keywords: university television; TV Unesp; visibility; semiotics; social networks. 


\section{Televisão multicast ${ }^{3}$ e a amplificação da visibilidade}

A distribuição de conteúdos audiovisuais em multiplataformas produz rupturas nas práticas de consumo das produções veiculadas em televisão, impondo às emissoras a necessidade de rever as bases que regem seus contratos comunicacionais. Isso porque a programação televisiva em fluxo do século XX, própria dos meios analógicos, capaz de erigir sistemas de comunicação televisivos hegemônicos de caráter privado ou público, passa a sofrer abalo significativo em suas estruturas, seus conteúdos e, consequentemente, nas estratégias para obter a atenção do público. A convergência digital acarreta, portanto, mudanças decorrentes, entre outros fatores, da proliferação das plataformas de distribuição, que atingiu todos os setores midiáticos e transformou, no caso do mercado televisivo, os hábitos de consumo do telespectador, uma vez que a programação em fluxo se viu compelida a disputar a audiência com os serviços de conteúdos sob demanda.

Motivadas principalmente pela variação nos índices de audiência e atentas às dinâmicas de circulação de conteúdos no ecossistema midiático convergente, as emissoras em sinal aberto são levadas a adotar estratégias para conquistar a atenção do público em circuitos massivos ou segmentados a partir da ampliação dos dispositivos capazes de entregar o sinal de televisão em qualquer tempo e lugar. Considerando, pois, as lógicas de distribuição dessa televisão ubíqua (SERRA, SÁ e SOUZA FILHO, 2015), a proposta é discutir em que medida as emissoras posicionadas à margem dos sistemas hegemônicos de televisão, como as emissoras universitárias brasileiras, se encontram, na perspectiva da semiótica das interações sociais (LANDOWSKI, 2014), diante da oportunidade de alcançar um novo posicionamento no contexto do consumo televisivo.

Estando as televisões reguladas tanto pelas lógicas inerentes à programação veiculada em fluxo quanto pelas da autoprogramação,

3 Multicast é o protocolo de transmissão de dados digitais, como sinais de TV ou vídeo, por meio de uma rede IP, sendo um tipo de comunicação de um para vários (ENTENDA COMO..., 2014). 
características da busca por demanda, a disponibilidade de conteúdos voltados a diversos segmentos em diferentes ambientes de fruição requer ações que os tornem visíveis tanto em processos de distribuição massiva quanto por nicho, conforme demonstrado na teoria da cauda longa (ANDERSON, 2006). Nesse sentido, a partir da observação das dinâmicas que regem tais fluxos comunicacionais nas diversas plataformas de difusão, o presente estudo procura analisar as características das formas de distribuição dos conteúdos da TV Unesp, emissora de televisão universitária sediada na cidade de Bauru, SP, no primeiro semestre de 2017, com foco nas ações de comunicação em redes sociais voltadas aos seus diferentes públicos de interesse.

Por ser a televisão de uma universidade com característica multicampi como a Universidade Estadual Paulista (Unesp), presente em 24 cidades do estado de São Paulo, torna-se imprescindível desenvolver estratégias de divulgação de sua produção para essas comunidades por meio dos canais de distribuição disponíveis nas diferentes plataformas. Além de transmitir em sinal aberto, a emissora também tem sua produção distribuída por operadoras de TV a cabo e via streaming por meio do site (www.tv.unesp.br) e do aplicativo UnespTV. Na busca da audiência em sinal aberto, assim como nos sistemas de distribuição fechados, as redes sociais constituem recurso efetivo de promoção da visibilidade dos conteúdos diante da ubiquidade televisiva.

Entre os grandes desafios que as televisões universitárias brasileiras enfrentam, interessa-nos neste artigo debater questões inerentes aos contratos enunciativos e modos de visibilidade, ou seja, como atingir o destinatário da comunicação no contexto midiático convergente marcado pela mobilidade e conectividade. Partimos da premissa de que o conteúdo é o elemento determinante para a apreensão do simulacro do enunciatário, isto é, para a definição do público ao qual se dirige. Por outro lado, no que diz respeito às TVs universitárias, notadamente as de caráter público, é esperada por parte da sociedade uma produção de conteúdo de interesse público, educativo, cultural e até mesmo institucional. De acordo com Wainer (2014), ao conhecer os públicos, é 
possível estabelecer um melhor direcionamento da programação e dos conteúdos, otimizando os recursos no sentido de serem endereçados com maior assertividade para o reconhecimento por parte da audiência. O autor ressalta que "a TV universitária disputa audiência e é assistida, mas não se sabe por quem, quantos ou quando" (WAINER, 2014, p. 7).

Trata-se, portanto, de um grande desafio para essas emissoras, visto que têm uma programação com conteúdo diferenciado em relação às emissoras comerciais, que geralmente mantêm uma grade de programas de entretenimento, bem como no âmbito da informação, jornalismo hard news ${ }^{4}$ ou infotainment. ${ }^{5}$ Televisões universitárias, notadamente aquelas de caráter público, prezam pela informação de qualidade e por abordagens que favoreçam a reflexão e o pensamento crítico sobre temáticas do interesse da sociedade. E diante da profusão de produtos e dos modos de distribuição disponibilizados aos diversos públicos que marcam a comunicação televisual na contemporaneidade, a articulação modal do "ser visto" depende cada vez mais de estratégias de comunicação que promovam a visibilidade das TVs universitárias nos contextos de fruição, sendo as redes sociais um recurso vigoroso para esse fim.

Partindo, pois, da hipótese de que as redes sociais são adjuvantes potenciais em um projeto de promoção da visibilidade dos conteúdos também no caso das emissoras universitárias, o presente artigo adota como procedimento metodológico inicial a análise das estratégias de divulgação da TV Unesp, observando as adaptações dos papéis actanciais dos agentes dessa comunicação em um ecossistema que tem potencialmente como adjuvantes as redes sociais, com base na teoria das interações sociais formulada por Landowski (2005). Após identificar as novas formas de circulação dos produtos televisivos em uma dimensão escópica multitelas, cotejam-se os resultados das análises das publicações no Facebook para a promoção da visibilidade, procurando evidenciar em que medida a ação dos algoritmos nesse processo reafirma, agora no

4 O modelo hard news tem origem no rádio norte-americano, com programação voltada 24 horas para notícias factuais (RITTER, 2016).

5 Infotainment é uma categoria de programas de emissoras televisivas que une informação e entretenimento (MENDES, 2015). 
ecossistema das mídias digitais, as estruturas hegemônicas ou mesmo monopolistas dos meios de comunicação analógicos, tendo em vista a lógica da monetização das ações nessas redes sociais.

\section{TV Unesp: a busca de posicionamento ante a audiência}

Conforme conceito adotado pela Associação Brasileira de Televisões Universitárias (ABTU), o segmento de televisão universitária tem algumas características que o difere das demais emissoras no país.

Televisão universitária é aquela produzida no âmbito das IES ou por sua orientação, em qualquer sistema técnico ou em qualquer canal de difusão, independente da natureza de sua propriedade. Uma televisão feita com a participação de estudantes, professores e funcionários; com programação eclética e diversificada, sem restrições ao entretenimento, salvo aquelas impostas pela qualidade estética e boa ética (PRIOLLI e PEIXOTO, 2004, p. 5).

Porém, inúmeras são as discussões sobre qual deve ser o modelo de uma televisão universitária. Pelo fato de as instituições de ensino superior (IES) terem suas próprias dinâmicas, é possível afirmar que não existe um modelo de TV universitária que possa ser replicado e/ou servir de base para a criação ou estruturação desse segmento. Para Magalhães (2013, p. 11), a TV universitária é diversa, assim como são as IES que as mantêm. Nesse sentido, a TV Unesp se caracteriza como uma emissora universitária mantida por uma instituição pública, a Universidade Estadual Paulista (Unesp).

Afiliada à TV Brasil desde 2014, emissora pública da Empresa Brasil de Comunicação (EBC), a programação da TV Unesp é integralmente voltada ao interesse público. Nessa perspectiva, Machado Filho e Ferreira (2012) argumentam que a TV Unesp coloca em prática um potencial de cidadania ao se dirigir aos seus públicos sem nenhum tipo de vínculo comercial, buscando sempre "manter uma grade de programação que traga ao mesmo tempo a qualidade de imagem, a interatividade e os conteúdos que interessem diretamente ao público em sua formação 
cidadã". (MACHADO FILHO e FERREIRA, 2012, p. 11). Acrescenta-se a isso a aproximação da pesquisa acadêmica ao dia a dia da audiência por meio da exibição de programas de divulgação científica, com destaque para as atividades de ensino, pesquisa e extensão realizadas pela Unesp.

Diante das mudanças e das possibilidades criadas pela digitalização dos meios, a definição do posicionamento da emissora nesse contexto, enquanto destinador da comunicação, impõe-se à adoção de ações que respondam às demandas inerentes ao querer ser vista, ser conhecida, por meio de conteúdos que atendam às expectativas de seus públicos. Implantada no paradigma da convergência das mídias, a TV Unesp iniciou suas transmissões em 4 de novembro de 2011 com o intuito de se posicionar como uma televisão universitária com foco na divulgação institucional, científica, cultural, educativa e de prestação de serviços.

De acordo com o plano estratégico ${ }^{6}$ que rege as tomadas de decisões na emissora, a TV Unesp está alinhada aos preceitos de emissoras de interesse público e tem entre seus propósitos a divulgação do conhecimento produzido na universidade por meio de conteúdos audiovisuais de relevância para sua audiência. Porém, para atingir tais objetivos, a emissora está atenta às transformações da comunicação enquanto objeto dinâmico, na concepção proposta por Barros (2003), responsável pela circulação de conteúdos. O desafio é pensar em novas formas para disponibilizar conteúdos televisivos também em outras plataformas midiáticas, ampliando, assim, a visibilidade da experiência de uma televisão universitária em base convergente inserida em um processo contínuo de programação e manipulação, numa perspectiva semiótica dos regimes das interações sociais, conforme veremos adiante.

De modo a articular essa veiculação de conteúdos em diferentes plataformas de distribuição, as áreas ligadas à produção trabalham em conjunto no desenvolvimento dos programas, nas postagens no site e nas redes sociais, bem como na captação de conteúdos por meio da

6 O Plano Estratégico da TV Unesp foi elaborado em 2016 e prevê mudanças para a emissora durante o quadriênio 2017-2020. Trata-se de um documento físico de posse da emissora. 
participação dos públicos. Cabe ressaltar que o site da TV Unesp também tem a opção de transmissão em streaming, que está sintonizada com a programação do sinal aberto, ou seja, no mesmo momento em que o programa está sendo transmitido pelo ar, caso o espectador opte por assistir via computador/tablet/smartphone, é possível acompanhar em tempo real. A emissora também possui um canal no YouTube que hospeda tudo que já foi ao ar, permitindo acesso aos conteúdos a qualquer momento.

Além dessas opções, no início de 2016, foi lançado o aplicativo UnespTV, com toda a programação para ser acessada por demanda, podendo ser baixado pelos sistemas $i O S$ ou Android. O site, além de funcionar como um portal que integra todas as informações e os conteúdos produzidos pela emissora, também tem a capacidade de armazenamento e recuperação de dados audiovisuais. Nesse ambiente, a participação do público se concretiza com força nas redes sociais, que passaram a ter cada vez mais relevância nas relações de comunicação e podem ser entendidas como ambientes de diálogo em processos comunicativos contemporâneos.

\section{Dimensão escópica e posições de comunicação}

Os desafios para o alcance de maior visibilidade da TV Unesp podem ser compreendidos por meio dos regimes de visibilidade entre sujeitos em relações de comunicação, na esteira das formulações de Eric Landowski (1992). Trata-se de uma necessidade de a emissora disseminar seus conteúdos de forma inovadora para captar a atenção dos diferentes segmentos de observadores aos quais pretende se mostrar nos sistemas de distribuição de sinais broadcast ${ }^{7}$ e broadband. ${ }^{8}$ A dimensão escópica evidencia a necessidade de existir uma relação entre protagonistas que pressupõe reciprocidade, na qual um dos protagonistas vê e o outro é

7 Transmissão clássica unidirecional MPEG-2 de fluxo de transporte baseado, como DVB-T, DVB-S ou DVB-C (ETSI, 2010, p. 9, tradução nossa).

8 Transmissão em banda larga, sempre em conexão IP bidirecional com largura de banda suficiente para streaming ou para baixar conteúdo A/V (ETSI, 2010, p. 9, tradução nossa). 
visto, constituindo-se, assim, a sintaxe do ver, inserida no âmbito das relações de intersubjetividade, nas quais os dispositivos abstratos que as organizam estão vinculados a determinado tipo de "saber" entre os sujeitos.

Partindo do pressuposto de que as ações implicadas nas modalizações do "ver" estão diretamente relacionadas ao que se pretende mostrar, entende-se que qualquer comunicação apresente relações de pressuposição recíproca entre sujeitos, ou seja, um que vê e outro que é visto, estando ambos em presença e diante da imagem que o sujeito visto cria para aquele que o vê. Entre os enunciatários estão atores semióticos que cumprem papéis temáticos de telespectadores da comunidade unespiana, comunidade em geral de internautas etc. O sujeito que é visto, ou seja, a própria emissora é, em termos semióticos, destinador da comunicação. Para que essa relação de visibilidade se concretize de fato, é imprescindível que o sujeito que se mostra queira ser visto pelo outro.

As relações de visibilidade também pressupõem uma dinâmica determinada, uma "fonte de luz", de acordo com Landowski (1992), para que o objeto da comunicação (aquele que é visto) possa chamar atenção do observador (aquele que vê).

Ora caberá ao observador estabelecer as condições de uma "boa visibilidade" (notadamente por uma organização apropriada de suas relações espaçotemporais com o objeto); ora, ao contrário, será o sujeito virtualmente observável que, procurando ele próprio, de certa forma, "fazer-se ver", organizará o dispositivo requerido para a "captação do olhar" de um observador potencial (LANDOWSKI, 1992, p. 89).

Nesse caso, é possível considerar como "fonte de luz" as estratégias de divulgação desenvolvidas nas redes sociais pela TV Unesp com vistas a promover a audiência. Para captar o olhar do observador e se fazer interessante, há necessidade de se tornar visível e presente para seus públicos em potencial. Essa busca por novas formas de ser percebida, atraindo os olhares, consiste em uma "reprogramação" de divulgação da emissora na perspectiva da teoria das interações sociais postulada por Landowski (2014), principalmente no que tange aos conteúdos sob 
demanda disponibilizados tanto no site institucional quanto no aplicativo UnespTV.

Nos regimes das interações sociais, a programação e o acidente estão relacionados aos modos de existência, enquanto o ajustamento e a manipulação se relacionam com os modos de ação, conforme descritos por Landowski (2014) no quadrado elíptico abaixo. Esses quatro regimes de interação formam um sistema dinâmico observável nas práticas sociais, admitindo não apenas deslocamentos de um para o outro, mas a ocorrência de concomitâncias. Ao articular os princípios e os procedimentos subjacentes aos regimes de interação no quadrado semiótico, o autor demonstra como as relações se interdefinem e se intercambiam em práticas sociais, conforme Quadro 1.

Quadro 1: Quadrado semiótico - os quatro regimes de interação social

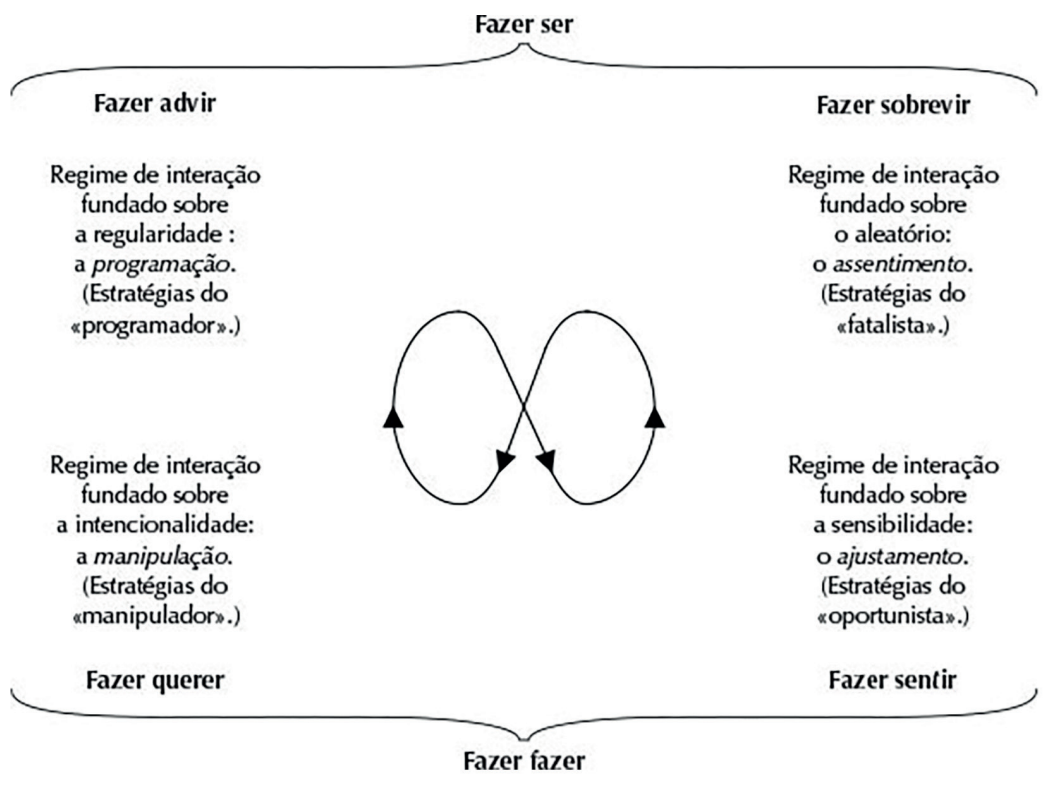

Fonte: (LANDOWSKI, 2005, p.72)

No caso da utilização das redes sociais para dar visibilidade a uma TV universitária em plataformas multicast, observamos uma intervenção 
nitidamente orientada pelos regimes de programação e de manipulação. No regime da manipulação, o sujeito é motivado à ação em função dos procedimentos persuasivos, fundados na intencionalidade, em que se manifestam as motivações e as razões do sujeito (LANDOWSKI, 2014). A manipulação pressupõe, por um lado, um sujeito que quer que o outro queira e, de outro, a existência de um sujeito de vontade capaz de avaliar os valores em jogo e aderir ou não ao contrato proposto. Essa "reprogramação" no modo de se tornar visível para uma audiência que não está no sistema de transmissão broadcast altera a regularidade estabelecida no regime de programação vigente nos modos de se fazer ver da emissora no sistema de distribuição aberta. Considerando que, no regime de interação da programação, fundado nas regularidades dos condicionamentos socioculturais, a chamada nas redes sociais para assistir às produções da TV Unesp implica uma nova programação que altera práticas nas relações entre sujeitos, isto é, emissora e público.

Ao se pensar nas estratégias de divulgação de um programa da emissora, a TV Unesp enquanto destinadora da comunicação sincretiza, ao mesmo tempo, o papel de enunciador ante os diversos públicos. Isso porque cada programa tem características específicas em arranjos enunciativos e discursivos que direcionam a forma de se comunicar com a audiência de diferentes maneiras, criando um simulacro de cada programa, de modo a despertar o interesse de um determinado público que fará uma imagem do programa e se identificará com o que é apresentado. Trata-se, pois, da interação entre esses sujeitos na relação da comunicação, mas para que ela ocorra, é preciso que o observador se identifique com aquilo que é mostrado, consolidando o regime de visibilidade no qual "de um lado todo 'sujeito visto' é, se assim podemos dizer, logicamente responsável se não pela maneira como é percebido, ao menos pelo próprio fato de sê-lo" (LANDOWSKI, 1992, p. 89). Isso reitera a importância de se pensar a forma como o sujeito que quer ser visto se "apresentará", uma vez que o simples fato de existir não garante a evidência de um sujeito visível. 


\section{Redes sociais: caminho para a visibilidade?}

Em que medida a adoção das redes sociais para promover a audiência dos conteúdos de uma TV universitária se apresenta como um recurso efetivo de visibilidade em um ambiente midiático no qual a oferta de conteúdos audiovisuais é exponencial? Nesse sentido, partimos do pressuposto de que é importante ressaltar que as estratégias para dar visibilidade aos conteúdos de emissoras como a TV Unesp em redes sociais devem estar alinhadas à distribuição da programação, seja em transmissão em sinal aberto ou pela busca por demanda. E para que atenda ao propósito de ser vista, é necessário ainda considerar a adequação dos arranjos discursivos em cada rede social.

Neste trabalho, partiu-se de uma leitura semiótica da grade de programas da TV Unesp e da identificação do regime de interação regido pela programação nas formas de distribuição de sinais em dispositivos tecnológicos convergentes para produzir ações de divulgação por meio de redes sociais. As estratégias desenvolvidas nesse ambiente midiático resultam da busca pela visibilidade de uma emissora broadcast ante a possibilidade de atuar também na distribuição por demanda. Dessa forma, no eixo da programação/manipulação, há um novo posicionamento da TV Unesp, tentando construir novos programas narrativos para estar em conjunção com seu objeto-valor, isto é, ser visível e relevante para diferentes públicos.

Com esse propósito, foram identificados quatro programas da emissora cujos discursos e simulacros de enunciatários apresentam aderência às redes sociais com potencial para a experimentação. Esse critério determinou a seleção dos programas Artefato, Som e Prosa, Unesp Notícias e Gestão Unesp para subsidiar a análise das ações da emissora nas redes sociais.

O programa semanal Artefato ${ }^{9}$ aborda temas ligados a arte, tecnologia e cultura, como fotografia, design, artes plásticas, música, moda, literatura e cinema e tem espaço de entrevistas que busca aprofundar o

9 Descrição do programa disponível em: http://www.tv.unesp.br/artefato/sobre. 
debate em torno das expressões artísticas contemporâneas. Tem a particularidade de ser produzido em temporadas.

Som e Prosa ${ }^{10}$ é um programa semanal que fortalece a diversidade musical presente no estado de São Paulo e conta com a participação de compositores de diferentes gêneros, da música caipira ao rap, do heavy metal à MPB. Os músicos apresentam as obras de seu repertório no estúdio da TV Unesp e discutem temas do cenário musical com o objetivo de compartilhar experiências e trazer ao público diversos pontos de vista.

Unesp Notícias ${ }^{11}$ é um telejornal diário que leva ao ar informações e reportagens com foco em utilidade pública, prestação de serviço, cultura e ciência com abordagem aprofundada dos fatos de interesse dos cidadãos. Emprego, saúde, economia, vida cultural e política da cidade, desafios para a educação, projetos das universidades que aproximam a comunidade da ciência, inovações tecnológicas e soluções para o meio ambiente, tudo isso faz parte da pauta diária do Unesp Notícias.

Com viés institucional, o Gestão Unesp ${ }^{12}$ está direcionado às atividades administrativas da Unesp. $\mathrm{O}$ ensino, a pesquisa e a extensão universitária são o foco de entrevistas com reitores e pró-reitores da universidade, que informam suas ações e discutem sobre os desafios da gestão de uma comunidade composta de discentes, docentes e servidores técnico-administrativos presentes em 24 cidades do estado de São Paulo.

Dos programas selecionados, apenas o Artefato e o Som e Prosa têm página individual no Facebook, ou seja, uma fanpage. Sendo páginas específicas dos programas voltadas à interação com o público, apresentam engajamento de uma audiência segmentada e alinhada ao simulacro de enunciatários interessados nesses conteúdos. Uma audiência jovem, conectada e que interage a partir dos dispositivos móveis. Diante dessa realidade, observou-se que a emissora demandava pouco esforço para promover esses conteúdos via redes sociais, momento em que enxergou

10 Descrição do programa disponível em: http://www.tv.unesp.br/someprosa/sobre.

11 Descrição do programa disponível em: http://www.tv.unesp.br/unespnoticias/sobre.

12 Descrição do programa disponível em: http://www.tv.unesp.br/gestaounesp/sobre. 
a necessidade de criar estratégias iniciais de divulgação desses conteúdos que pudessem ser aplicadas ao que já estava vigente.

Com o intuito de vincular as fanpages do Artefato e do Som e Prosa à fanpage institucional da TV Unesp, uma das ações realizadas foi o compartilhamento de publicações dessas páginas na página da emissora para que os fãs da página institucional pudessem conhecer o conteúdo postado especificamente nesses programas e, caso tivessem interesse, curtissem também as outras páginas. Assim, os seguidores da página institucional, que é a mais acessada, passaram a conhecer melhor os conteúdos voltados a públicos mais específicos. Além disso, com a colaboração dos funcionários, foi adotada a estratégia de publicações sobre os bastidores das gravações dos programas para modalizar o público a um querer saber com o intuito de estreitar o relacionamento da emissora com os fãs.

Já para o telejornal Unesp Notícias, voltado ao público em geral, a ação se concentrou na melhoria dos textos das publicações na fanpage da TV, com a redução do número de caracteres e a padronização do uso da hashtag Unesp Notícias no início da postagem (Figura 1), para que o fã da página institucional identificasse de forma imediata que aquele conteúdo remetia a uma notícia do telejornal. Os recursos utilizados nas postagens são frames, GIFs ou trechos em vídeo das matérias com o objetivo de despertar a atenção e promover o engajamento do fã, que poderá curtir e compartilhar o conteúdo em suas redes sociais, conforme Figura 1 (TV UNESP [Facebook], s. d.). 
Figura 1 - Exemplo de postagem do programa Unesp Notícias na fanpage da TV Unesp

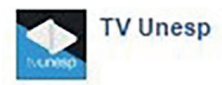

$$
14 \text { de fevereiro às 21:00 }
$$

\#UnespNoticias Uma pesquisa da Unesp em Araraquara pode revolucionar 0 tratamento do diabetes. Seria o fim das injeções de insulina? Veja na reportagem. \#diabetes \#insulina

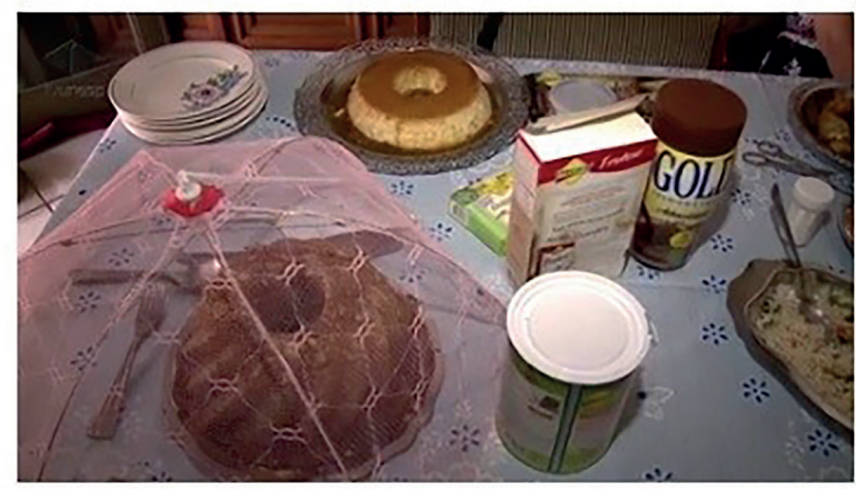

\begin{tabular}{|c|c|c|c|}
\hline \multicolumn{3}{|c|}{92.730 pessoas alcançadas } & Impulsionar publicagāo \\
\hline \multicolumn{4}{|c|}{31 mil visualizaçōes } \\
\hline I Curtir & Comentar & $\Rightarrow$ Compartilhar & $\theta$ \\
\hline
\end{tabular}

427 compartilhamentos

Fonte: Fanpage institucional TV Unesp

Ações direcionadas à comunidade unespiana foram realizadas por meio da fanpage institucional da TV Unesp com o compartilhamento de páginas relacionadas à universidade para divulgar conteúdos de outros interesses, como 41 anos Unesp, Cursinho Principia, Cursinho Primeiro de Maio, Ativa Parkinson, Observatório Didático de Astronomia "Lionel José Andriatto” - Unesp/Bauru, visando aproximar os públicos dessas outras fanpages e fazer com que conhecessem a TV Unesp. Especificamente voltado ao campus da Unesp de Bauru, cidade onde a emissora está sediada, criou-se um banner com informações sobre a TV para ser divulgado em grupos fechados de Facebook dos cursos das diferentes 
faculdades com o intuito de convidar alunos para curtirem a página da TV Unesp e os programas Artefato e Som e Prosa.

A retomada do Twitter foi outra ação divulgada no Facebook para informar aos fãs sobre a presença da TV Unesp nessa outra rede social. No âmbito do marketing digital, foram adotadas duas ferramentas para dar suporte às ações nessa rede: a primeira foi hashtagify.me ${ }^{13}$ site de acompanhamento de hashtags e assuntos relacionados onde se pode acompanhar os influenciadores on-line, o padrão de utilização e as hashtags do momento. Com o uso dessa ferramenta, foi possível observar as hashtags relacionadas a Bauru (Unesp, Bauru, vestibular etc.), sendo que o principal assunto dessas hashtags dizia respeito ao tema do vestibular. Por isso, buscou-se interagir com esses eventuais futuros estudantes da Unesp, divulgando os conteúdos da emissora para esse público.

A segunda ferramenta utilizada para auxiliar essa retomada foi a laterbro.com, ${ }^{14}$ cuja finalidade é o agendamento de tweets mais voltados para promover páginas da TV sobre assuntos já publicados, geralmente conteúdos atemporais, mas de interesse de segmentos determinados (Figura 2). A partir do perfil do Twitter da TV Unesp, foi criada uma lista de transmissão intitulada "Unesp", com o intuito de direcionar as publicações da emissora no Twitter a perfis oficiais ligados à universidade, entre os quais destacamos perfis de outros campi, dos institutos de pesquisa e dos projetos institucionais. O bom uso dessa plataforma pode servir como uma nova maneira de disseminação dos conteúdos produzidos pela emissora, pois, com eficaz direcionamento das hashtags e uma programação de tweets assertiva, é possível interagir com os públicos de interesse e se mostrar presente para se fazer visível, conforme Figura 2 (TV UNESP [Twitter], s. d.).

13 Essa ferramenta mostra hashtags relevantes e relacionadas a determinada palavra-chave em forma de mapa mental. Disponível em: http://hashtagify.me/.

14 Essa ferramenta é um serviço on-line que permite que usuários das redes sociais Facebook e Twitter criem posts programados em suas linhas de tempo. Disponível em: http://laterbro. $\mathrm{com} /$. 
Figura 2 - Exemplo de tweet publicado no perfil do Twitter da TV Unesp

TV Unesp @tvunesp-10 de fev

Você já conhece o quadro "Vamos Viajar?", do Artefato? Acesse

tv.unesp. br/artefato e não perca as edições desta temporada!

4

TV Unesp @tvunesp·10 de fev

É dia de Artefato! Assista hoje sobre cultura popular, viagens e,

gênero e sexualidade. Ficou curiosx? Acesse bit.ly/2k8FmM9

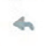

TV Unesp @tvunesp - 8 de fev

Tem clipe novo da banda O Psiconauta, que passou pelo palco do Som e Prosa em dezembro com um som dez! Dá um play aí

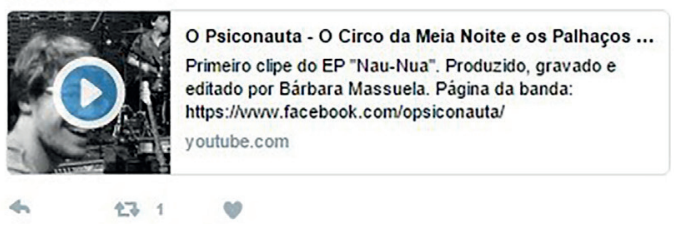

Fonte: Perfil do Twitter da TV Unesp

Observa-se que as estratégias em redes sociais, sobretudo com relação às fanpages, estão alinhadas com o propósito de estabelecer relacionamento e vínculo com os públicos, gerando maior proximidade e visibilidade para a marca/empresa. No entanto, com as constantes mudanças dos algoritmos de plataformas de redes sociais como Facebook e Instagram, por exemplo, publicações com alcance do tipo orgânico, isto é, não pagas são vistas por um percentual restrito de seguidores da página. Já o alcance do tipo pago é maior quanto maior o valor investido na publicação, alcançando tanto seguidores da página quanto outras pessoas que se convertem em seguidores.

Chamados de EdgeRank,15 os algoritmos do Facebook são um conjunto de regras definido pela própria rede social para eleger o que é mais importante para ser visualizado pelo público em geral. Esse algoritmo influencia diretamente nos resultados dos negócios feitos pela rede

15 Disponível em: http://www.shapeweb.com.br/blog/2018/02/27/06-mudancas-do-novo-algoritmo-do-facebook/. Acesso em: 29 maio 2018. 
social, pois passou a priorizar publicações com interações entre pessoas e não com empresas, conforme a mudança de algoritmol6 anunciada por Mark Zuckerberg em seu perfil pessoal no dia 11 de janeiro de 2018, momento em que a rede social passou a priorizar publicações feitas por amigos e familiares, deixando em desvantagem postagens feitas por páginas empresariais, conforme Figura 3 (ZUCKERBERG, 2018).

Figura 3 - Anúncio de Mark Zuckerberg

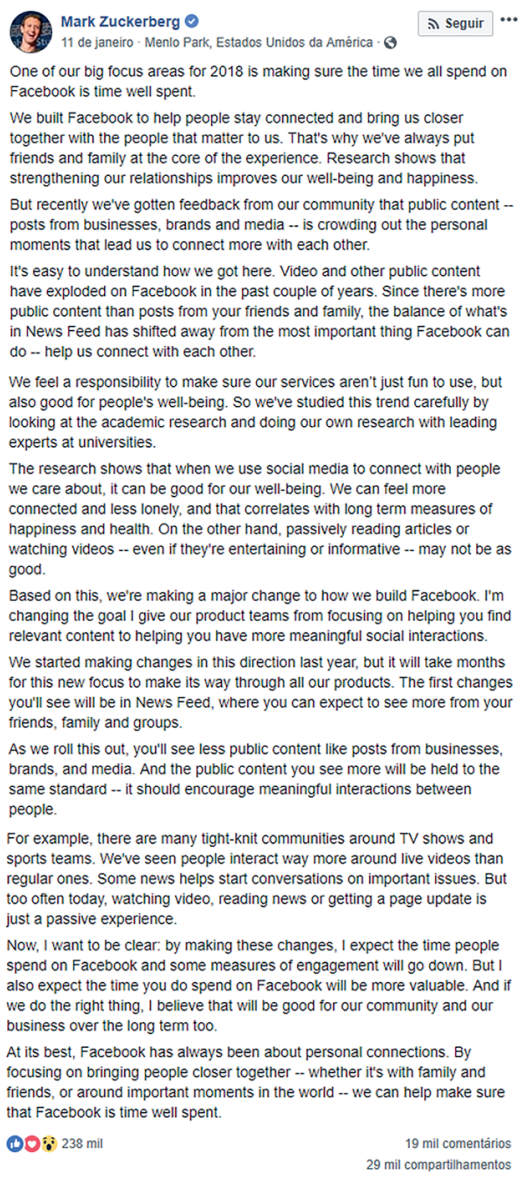

Fonte: Facebook

16 Disponível em: https://resultadosdigitais.com.br/blog/facebook-mudanca-algoritmo/. Acesso em: 29 maio 2018. 
As publicações da página da TV Unesp são do tipo orgânica e isso pode explicar a baixa interação de seu público com os conteúdos, visto que tem em torno de 17 mil curtidas em sua página no Facebook, porém o alcance é baixo, em média de cinco a 10 curtidas por publicação. A central de ajuda do Facebook (QUAL É A DIFERENÇA..., s. d.) esclarece que o alcance orgânico se refere ao número total de pessoas que viram as publicações por meio de uma distribuição não paga; o alcance pago se refere ao número total de pessoas que viram as publicações como resultado de anúncios; e, por último, o alcance total engloba a forma orgânica e a paga, pois é um somatório dos dois tipos anteriores.

A nova conduta do Facebook tem representado uma mudança significativa nas ações de visibilidade das páginas institucionais, uma vez que, para serem vistas, não basta que as empresas foquem em conteúdo de qualidade, é necessário promovê-lo em forma de anúncios pagos para gerar alcance. Nesse sentido, por ser uma instituição sem fins lucrativos, a TV Unesp encontra dificuldades em atingir o objetivo de engajar seus públicos em redes sociais, considerando que não dispõe de recursos para investimento em divulgação. Por isso, a perspectiva de engajamento incide diretamente na produção de conteúdos de interesse de segmentos de público que possam promover maior interação entre seus seguidores, buscando se adaptar aos algoritmos para obter um alcance significativo. Ou seja, o único caminho capaz de promover uma visibilidade nessa rede social é a força de conteúdo relevante para os diferentes segmentos de público.

\section{Considerações finais}

O percurso apresentado no presente artigo demonstra que as redes sociais só podem ser um importante adjuvante das emissoras de televisão públicas como a TV Unesp caso estas venham a se inserir no sistema mercadológico que rege as plataformas de redes sociais, aderindo à prática de promoção de seus conteúdos por meio de anúncios pagos. Os resultados da presente análise confirmam isso. 
É notório que, desde seu surgimento, a televisão sempre contou com o auxílio de outros meios para divulgar seus programas. Entretanto, as articulações entre organizações e conglomerados de mídia no sistema analógico não permitiam que os veículos menores, alternativos, regionais, tivessem visibilidade expressiva entre as audiências. $\mathrm{O}$ consumo de produções realizadas fora dos circuitos comerciais representava exceções dirigidas a segmentos de público muito específicos ou mesmo alternativos. No ambiente digital, essa dinâmica se repete. As redes sociais teriam, em tese, maior potencial de divulgação, de acesso dos públicos aos conteúdos de interesse. Entretanto, o fato de as produções estarem disponíveis em plataformas como o Facebook não garante a visibilidade pretendida pelas emissoras não hegemônicas, conforme demonstrado neste trabalho.

Conclui-se que, embora haja uma narrativa sobre a existência de uma comunicação mais horizontalizada proveniente da convergência midiática na qual a busca pela adesão do enunciatário passa pelas lógicas das redes sociais, as estratégias/ações adotadas na TV Unesp, por exemplo, para divulgar seus programas e mobilizar diferentes públicos não significa uma quebra de paradigma nos hábitos de consumo. Ao buscar a audiência segmentada, mensurável por sistemas estatísticos informatizados, observa-se que a possibilidade virtual de a emissora alcançar um novo posicionamento diante do contexto midiático, digital e contemporâneo, usufruindo de todas as possibilidades tecnológicas de distribuição desses conteúdos, não se concretiza no âmbito de uma lógica segmentada que seja representativa. Para se fazer visível, é necessário buscar alternativas à dinâmica determinada pelos algoritmos, se é que isso é possível. 


\section{Referências}

ANDERSON, C. A cauda longa. Rio de Janeiro: Campus, 2006.

BARROS, L. M. Para que pesquisar? Comunicação: uma ciência social aplicada. In: DE LOPES, Maria Immacolata. (Org.). Epistemologia da Comunicação. São Paulo: Loyola, 2003.

BRASIL. Ministério da Ciência, Tecnologia, Inovações e Comunicações (MCTI). TV Digital, [s. d.]. Disponível em: http://www2.mcti.gov.br/index.php/tv-digital. Acesso em: 20 jan. 2017.

CUSTÓDIO, M. Facebook anuncia mudança no algoritmo: menos relevância para fanpages e mais para amigos e familiares. Resultados Digitais, 2018. Disponível em: https://resultadosdigitais.com.br/blog/facebook-mudanca-algoritmo/. Acesso em: 29 maio 2018.

ENTENDA COMO a transmissão multicast pode otimizar IPTV. Cianet, 8 jul. 2014. Disponível em: https://www.cianet.com.br/entenda-como-transmissao-multicast-pode-otimizar-iptv/. Acesso em: 13 jun. 2018.

EUROPEAN TELECOMMUNICATIONS STANDARDS INSTITUTE (ETSI). Technical Specification ETSI TS 102 796. Hybrid Broadcast Broadband TV. v. 1.1.1. França: ETSI, 2010. Disponível em: https://www.etsi.org/deliver/etsi_ts/102700_102799 /102796/01.01.01_60/ts_102796v010101p.pdf. Acesso em: jun. 2018.

LANDOWSKI, E. A sociedade re $e$ tida. Trad. Eduardo Brandão. São Paulo: Educ: Pontes, 1992.

. Interações arriscadas. Trad. Luiza Helena Oliveira da Silva. São Paulo: Estação das Letras e Cores: Centro de Pesquisas Sociossemióticas, 2014.

. Les interactions risquées. Limoges: Pulim, 2005.

MACHADO FILHO, F.; FERREIRA, M. F. TV pública e TV privada no Brasil: caminhos opostos na migração digital. In: CONGRESSO BRASILEIRO DE CIÊNCIAS DA COMUNICAÇÃO, XXXV, 2012, Fortaleza. Anais... Fortaleza: Intercom, 2012. Disponível em: http://www.intercom.org.br/sis/2012/resumos/R7-1176-l.pdf. Acesso em: 29 dez. 2016.

MAGALHÃES, C. M. Dossiê TV Universitária: 45 anos de experiência. Revista ABTU TV Universitária + TV Pública, ed. 1, n. 0, 2013. Disponível em: http://www.abtu.org.br/ WebSite/wp-content/uploads/2013/07/Revista-ABTU-00.pdf. Acesso em: 27 dez. 2016.

MENDES, G. P. C. A polêmica combinação de jornalismo com entretenimento. Observatório da Imprensa, ano 19, n. 991, 2015. Disponível em: http://observatoriodaimprensa. com.br/diretorio-academico/a-polemica-combinacao-de-jornalismo-com-entretenimento/. Acesso em: 13 jun. 2018.

MESQUITA, F. 06 mudanças do novo algoritmo do Facebook. Shapeweb, 2018. Disponível em: http://www.shapeweb.com.br/blog/2018/02/27/06-mudancas-do-novo-algoritmo-do-facebook/ Acesso em: 29 maio 2018.

PRIOLLI, G.; PEIXOTO, F. A TV Universitária no Brasil: os meios de comunicação nas instituições universitárias da América Latina e Caribe. ABTU, 2004. Disponível 
em: http://unesdoc.unesco.org/images/0013/001399/139903por.pdf. Acesso em: 29 dez. 2016.

QUAL É A DIFERENÇA entre alcance orgânico, pago e alcance total? Facebook, [s. d.]. Disponível em: https://www.facebook.com/help/285625061456389. Acesso em: 29 maio 2018.

RITTER, E. O encontro entre o hiperlocal e o global no hard news televisivo no canal de notícias norte-americano NYl. Revista Pauta Geral - Estudos em Jornalismo, Ponta Grossa, v. 3, n. 2, p. 97-113, jul.-dez. 2016. Disponível em: http://www.revistas2.uepg. br/index.php/pauta/article/view/9005/5376. Acesso em: 13 jun. 2018.

SERRA, P.; SÁ, S.; SOUZA FILHO, W. A televisão ubíqua. Covilhã: Livros LabCom, 2015. Disponível em: http://www.labcom-ifp.ubi.pt/ficheiros/20150529-201507_pserrassawfilho_tvubiqua.pdf. Acesso em: 20 jan. 2017.

TV UNESP. Fanpage institucional da TV Unesp. Facebook, [s. d.] Disponível em: https://www.facebook.com/tvunesp/?fref=ts. Acesso em: 10 maio 2017.

TV UNESP. Perfil institucional da TV Unesp. Twitter, [s. d.]. Disponível em: https:// twitter.com/tvunesp. Acesso em: 10 maio 2017.

TV UNESP. Sítio eletrônico. Disponível em: http://www.tv.unesp.br. Acesso em: 27 dez. 2016.

WAINER, J. Processos de criação e gestão de uma TV Universitária. Revista ABTU TV Universitária + TV Pública, v. 1, ed. 2, n. 1, 2014. Disponível em: http:// www.abtu.org.br/WebSite/wp-content/uploads/2014/11/Revista-ABTU-n01-baixa-resolu\%C3\%A7\%C3\%A3o.pdf. Acesso em: 20 dez. 2016.

ZUCKERBERG, M. One of our big focus areas... Publicação no perfil pessoal do Facebook. Califórnia, 2018. Disponível em: https://www.facebook.com/zuck/ posts/10104413015393571 Acesso em: 29 maio 2018.

\section{Sobre as autoras}

Ana Silvia Lopes Davi Médola - Livre-docente em Comunicação Televisual pela Universidade Estadual Paulista (Unesp). Docente permanente do Programa de Pós-graduação em Comunicação da mesma instituição. Diretora da TV Unesp (2010-2017). Líder do Grupo de Estudos Audiovisuais (GEA).

Mariane Frascareli Lelis - Mestre em Comunicação e bacharel em Comunicação Social: Relações Públicas pela Unesp.

Data de submissão: 06/08/2018

Data de aceite: 22/05/2019 